\title{
A percepção do usuário quanto ao projeto padrão adotado na arquitetura escolar brasileira
}

\section{User's perception of the standard project adopted in the brazilian scholar architecture}

José Henrique C. Cordeiro ${ }^{1}$, Lisiê Kremer Cabral $^{2}$, Adriana Portella ${ }^{1} \&$ Ana Lúcia Costa de Oliveira ${ }^{1}$

\author{
${ }^{1}$ Universidade Federal de Pelotas, Pelotas, Brazil \\ ${ }^{2}$ Universidade Federal do Rio Grande do Sul, Porto Alegre, Brazil \\ Correo electrónico:joseccordeiro@yahoo.com.br
}

\section{Resumo}

No Brasil, no início do período republicano, com o entendimento da educação como ferramenta progresso, surgiu a prática da criação de instituições escolares originadas em um modelo padrão. O processo de industrialização do país, aliado à normatização da arquitetura, fez com que a reprodução de projetos padronizados se tornasse comum a nível nacional, embasada na justificativa do desenvolvimento através da racionalização e estandardização da construção. Nos anos 1990, o país implementou novos programas sociais, um deles embasado na educação em turno integral com nova estrutura pedagógica, materializado nos Centros Integrais de Atenção à Criança e ao Adolescente - CIACs - escolas de projeto padrão com autoria do arquiteto João Filgueiras Lima. Em 1992, o programa que originou as escolas CIAC foi alterado e esse modelo de instituição passou a ser chamado de CAIC - Centro de Atenção Integral à Criança e ao Adolescente, tendo poucas alterações em seu projeto arquitetônico e mantendo o mesmo programa pedagógico já utilizado. Através de um estudo de caso no CAIC da cidade de Pelotas, em que foram realizadas entrevistas com professores da escola para compreender sua percepção frente a uma escola de arquitetura padrão, este artigo apresenta os CAICs e seu histórico, assim como trata da apropriação e da formação de identidade dos usuários no contexto do projeto padrão. O trabalho evidencia que esse tipo de atuação já coloca a futura edificação sujeita a prováveis intervenções, de forma que o usuário possa sanar os problemas oriundos da falta do planejamento participativo na fase projetual da escola.

Palavras-chave: Percepção do usuário; arquitetura escolar; projeto padrão; apropriação; senso de lugar: 


\begin{abstract}
In Brazil, at the beginning of the republican period, with the understanding of education as a tool for progress, the practice of creating school institutions based on a standard model emerged. The country's industrialisation process, together with the standardisation of architecture, meant that the reproduction of standardised projects became common at national level, based on the justification of development through the rationalisation and standardisation of construction. In the $1990 \mathrm{~s}$, the country implemented new social programmes, one of them based on full-time education with a new pedagogical structure, materialised in the Comprehensive Centres for Child and Adolescent Care - CIACs - standard design schools designed by the architect João Filgueiras Lima. In 1992, the program that originated the CIAC schools was changed and this model institution was renamed CAIC - Comprehensive Care Centre for Children and Adolescents, with few changes in its architectural design and maintaining the same pedagogical program already in use. Through a case study in the Pelotas CAIC, in which interviews were conducted with school teachers to understand their perception of a school with standard architecture, this article presents the CAICs and their history, as well as deals with the appropriation and identity formation of users in the context of the standard project. The work shows that this type of performance already puts the future building subject to probable interventions, so that the user can remedy the problems arising from the lack of participatory planning in the design phase of the school.
\end{abstract}

key words: User perception; school architecture; standard design; appropriation; sense of place.

\title{
Introdução
}

O processo de evolução das edificações escolares no Brasil iniciou no período do Império. As escolas eram instaladas em ambientes inadequados e adaptados ao seu uso, exceto quando voltadas às classes mais abastadas. Entre 1889 e 1930, após a mudança do governo imperial para o republicano, surgiu a compreensão da educação como instrumento de desenvolvimento social, resultando em uma abordagem em que novas instituições de ensino começaram a ser construídas com a mesma tipologia arquitetônica.

Com o avançar das tecnologias e com a justificativa de padronizar, racionalizar e acelerar a construção, se tornou comum a prática do projeto padrão em edifícios escolares. O conceito de projeto padrão consiste na padronização do programa de necessidades de uma edificação e na reprodução de seu projeto arquitetônico em distintas localidades, independente de variações de clima e cultura. Trabalhos como de Waisman (1985), Gutiérrez (1989) e Gaite (2003) abordam a utilização de projetos padrão como uma ação problemática, pois esse tipo de projeto não leva em consideração as características histórico-culturais das localidades em que são inseridos. 
No Brasil, na década de 1990, com a recente constituição democrática de 1988 e o fim da ditadura militar, o governo vigente, com o discurso de democratização do ensino e atendimento social, criou programas visando integrar ações de educação, saúde e cultura. Para a materialização desse objetivo foram criados os Centros Integrais de Atendimento à Criança e ao Adolescente (CIACs), instituições educacionais que previam em seu plano de necessidades, além de salas de aula, alas médicas, auditórios, biblioteca e ginásio.

Entretanto, em 1992, com a crise do governo brasileiro e o impedimento do então Presidente Fernando Collor, o programa que fundamentou os CIACs foi alterado, caracterizando-se por reduções no projeto arquitetônico e no número de instituições a serem construídas. Essa nova proposta foi denominada Centro de Atenção Integral à Criança e ao Adolescente (CAIC), e permaneceu pouco alterada quando comparada ao projeto antecessor (CIACs), reduzindo apenas a área a ser edificada em cada escola, permanecendo o mesmo programa de necessidades.

Dentro dessa temática, o presente artigo busca responder a seguinte pergunta: Como o projeto padrão de instituições escolares é percebido por seus usuários considerando questões de apropriação e senso de lugar? O objetivo é analisar como se dá pelo usuário a apropriação e a construção do senso de lugar em escolas de projeto padrão. Inicialmente é apresentado o contexto do surgimento de projetos padronizados na arquitetura escolar no Brasil, seu peso na formação da representação identitária do lugar e, por fim, a partir de um estudo de caso, é averiguado qual a percepção do usuário perante uma instituição de ensino de projeto padrão.

\section{Escolar no Brasil: Projeto Padrão, Identidade e ApropriaçãoArquitetura}

As instituições escolares no Brasil, até o início da Primeira República em 1889, eram instaladas em edificações precárias, não planejadas para seu uso, exceto as voltadas à população de classe econômica mais elevada (Schwartzman, 1982). Foi durante os anos de 1889 a 1930 que os governantes no Brasil passaram a entender a educação como sinônimo de progresso, de maneira que começaram a surgir programas escolares que objetivavam o acesso à educação de forma gratuita a toda população (Dórea, 2000). Nessa época, iniciou-se a implementação de um projeto arquitetônico tipo, o qual correspondia à utilização de plantas baixas similares, com poucas alterações nas fachadas, que variavam de acordo com a localidade em que o prédio seria inserido. Por se tratar das primeiras instituições brasileiras projetadas exclusivamente e especificamente para o uso escolar, foi nesse momento que a escola passou a ser reconhecida por sua representatividade como lugar. Essas edificações possuíam características ecléticas e um programa de necessidades enxuto, com monumentalidade em seu edifício. A tipologia dessas construções fazia referência à política e ao momento histórico do período (Azevedo, Bastos \& Blower, 2007; Faria Filho \& Vidal, 2000).

Estabelecendo-se a padronização dos novos métodos do processo de projeto e a normatização da arquitetura - com o objetivo de racionalizar a concepção e a construção do edifício - consolidou-se o conceito de padrão arquitetônico (Frampton, 2003; Ramón \& Pereira, 2010). Observa-se que alguns autores utilizam a nomenclatura 'projeto padrão' (Kowaltowski, 2013; Cabral, 2020) e outros 'projeto modelo' (Waisman, 1985; Gutiérrez, 1989; Gaite, 2003) como sinônimos para a estandardização dos projetos 
de arquitetura. O projeto modelo se refere à reprodução idêntica de algo já estabelecido anteriormente (Waisman, 1985). Percebe-se que o uso da terminologia projeto padrão, quando aplicada à definição do projeto modelo, não incorre em perda de significado ou alteração em seu sentido. Portanto, tendo em vista sua larga utilização de maneira acertada pela bibliografia, inclusive pelo Ministério da Educação do Governo Federal do Brasil (Fundo Nacional de Desenvolvimento em Educação [FNDE], 2017), escolheu-se, neste artigo adotar o termo projeto padrão.

O projeto padrão consegue atender à objetivos econômicos e de racionalidade construtiva de maneira satisfatória, a partir de um programa de necessidades padronizado (Corrêa, Mello \& Neves, 1991). A padronização de edificações institucionais também tem o objetivo de marcar e identificar o momento político de uma determinada época, sendo, essas construções referenciadas como assinaturas de seus idealizadores, principalmente por serem comumente instaladas em locais de visibilidade e destaque na cidade (Azevedo, Bastos \& Blower, 2007; Kowaltowski, 2013).

Durante o período do governo de Getúlio Vargas no Brasil, entre 1930 e 1945, fundamentou-se um novo método de ensino visando a democratização do acesso à educação. Isso culminou em um novo programa arquitetônico, que aliado às inovações construtivas, repetindo-se as ideias de padronização do projeto e racionalização da construção, resultou na implementação de novas escolas padrão (Segawa, 1997). Nessa época, a partir das ideias do educador brasileiro Anísio Teixeira, surge o conceito de 'escolas-parque' e 'escolas-classe', em que o programa de necessidades básico contava com espaços administrativos, gabinete médico e dentário, salas de aula, banheiros, e os modelos mais elaborados previam salas para uso especial, como para aulas de música, bibliotecas e auditórios (Kowaltowski, 2013; Dórea, 2000; Oliveira, 2007).

$\mathrm{Na}$ década de 1980, as ideias de Anísio Teixeira, referentes às escolas-parque, são retomadas pelo então vice-governador do estado do Rio de Janeiro no Brasil, Darcy Ribeiro. Essa ação resultou na construção dos Centros Integrados de Educação Pública (CIEPs), que inicialmente foram implementados somente no estado do Rio de Janeiro, mas, posteriormente, foram construídos em outros estados brasileiros, a exemplo do Rio Grande do Sul. Por sua vez, os Centros Integrais de Atendimento à Criança e ao Adolescente (CIACs), concebidos na década de 1990, a partir da experiência da execução tanto das escolas-parque, em 1950, quanto dos CIEPs, em 1980, representam uma evolução em relação a esses dois programas anteriores. Nos CIEPs e nos CIACs foram utilizados o conceito do projeto padrão, com a mesma justificativa de racionalização e normatização da construção (Kowaltowski, 2013).

Observa-se que mesmo com a economia e a rapidez obtida através da construção de uma edificação escolar baseada em um projeto padrão, existem perdas relacionadas às características da comunidade local onde o prédio é inserido, tais como aspectos de conforto e/ou representatividade cultural de seus usuários (Kowaltowski, 2013). Gaite (2003) aponta que não só a forma, mas também o sistema construtivo e os materiais utilizados são determinantes na apropriação cultural de uma edificação, uma vez que devem ser condizentes com os conhecimentos técnicos da mão de obra disponível na localidade em que o projeto é proposto. 
A compreensão das relações históricas entre o ambiente e o ser humano traz luz aos valores originados nos modos de pensar e agir de uma comunidade. O resultado dessas relações pode ser entendido como unidade cultural. Uma mudança nesses aspectos comportamentais gera a criação de novos valores que provocarão novos entendimentos a respeito da cultura dessa comunidade (Waisman, 1985). Caso essa consideração não seja percebida pelo projetista, há o surgimento de uma ruptura na identidade cultural local ou, ainda, ocorre a criação de uma nova identidade rasa e temporária. A arquitetura não é apenas objeto artístico, mas também ferramenta de desenvolvimento social (Gutiérrez, 1989).

Nesse sentido, conhecer o usuário da futura edificação, suas necessidades e aspirações é essencial para haver qualidade no final do processo construtivo. O projeto de arquitetura é resultado da interação entre projetista, usuário e ambiente (Tedeschi, 1978), e essa interação é ausente na utilização do projeto padrão. O conhecimento humanista e técnico a respeito da população, clima e cultura são inestimáveis ao arquiteto e urbanista, de forma que projetar em arquitetura é percorrer um extenso caminho de sucessivas tomadas de decisões (Gaite, 2003). O uso de definições previamente concebidas, sem a avaliação dos aspectos particulares de cada cidade, bairro e comunidade, podem provocar perdas para os seus usuários. Ignorar a existência da relação ser humano e ambiente no processo de projeto pode provocar o surgimento de 'não lugares', conceito já definido por Augé (1995).

Elaborar projetos arquitetônicos que não levam em consideração fatores históricos e culturais da comunidade na qual serão inseridos, podem gerar vazios culturais e enfraquecem sua representatividade. $\mathrm{Na}$ ausência de elementos que fortaleçam o sentimento de representação e apropriação, surge o entendimento de uma identidade incoerente, resultando em uma sobreposição de representações. Entender a identidade coletiva de uma comunidade e inseri-la em um projeto de arquitetura é materializar sua cultura atendendo suas demandas. A própria comunidade, na situação de implementação de um projeto padrão, começa a fazer adaptações para sanar problemas de falta de representatividade e apropriação do ambiente construído, de maneira que essas manifestações são entendidas como a identidade cultural do lugar (Gutiérrez, 1989). O senso de lugar - conceito relacionado ao vínculo das pessoas com o ambiente habitado (May, 1970 como citado em Shamai, 1991, p. 347) - compreende, ao mesmo tempo, a força motriz e a resultante dessas manifestações.

A partir do momento em que há esse tipo de interação, do ser humano e do lugar, há o surgimento de memórias e narrativas, surgindo o sentimento de pertença e representatividade. Fato que corrobora o argumento de Gutiérrez (1989), pois se um dia não houve uma relação de representação com o ambiente em que se vive, com o passar do tempo e a partir das interações sociais esse sentimento começa a surgir e se fortalecer, sobrepondo-se às representações anteriores já formadas.

Dentro desse contexto, o problema de pesquisa que se busca analisar neste artigo é que a implementação de um programa de educação que preconiza a utilização de escolas padrão não leva em consideração as particularidades do local onde essa escola está sendo inserida, ocasionando problemas identitários no indivíduo, pois há uma ruptura no processo de desenvolvimento de identidade de lugar. No item abaixo 
apresenta-se uma contextualização do CAIC, escola de projeto padrão inserida em todo território nacional do Brasil, estudo de caso desse artigo.

\section{De Centros Integrados de Atenção à Criança e ao Adolescente (CIAC) à Centro de Atenção Integral à Criança e ao Adolescente (CAIC)}

Em 1990, o então presidente do Brasil Fernando Collor iniciou um programa para criação de instituições de ensino em turno integral, que buscava aumentar as atividades de cunho social nos bairros carentes de municípios distribuídos pelo país (Sobrinho \& Parente, 1995). Dessa forma, o governo federal brasileiro estabeleceu o Projeto Minha Gente (Brasil, 1991), que objetivava criar ações voltadas à saúde, educação e desenvolvimento social relacionadas à criança e ao adolescente a partir de pré-escolas, creches, escolas de primeiro grau em tempo integral, postos de puericultura, espaços de convivência e práticas desportivas (Sobrinho \& Parente, 1995).

Concretizando a ideia de compilar em um único ambiente toda a estrutura necessária a esse plano do Governo, foram propostas as instituições de ensino denominadas 'Centros Integrados de Atenção à Criança e ao Adolescente' (CIAC). A edificação, de projeto padrão, foi desenvolvida pelo arquiteto brasileiro João Filgueiras Lima, com a utilização de elementos estruturais pré-fabricados em argamassa armada. Essa tecnologia construtiva, aliada à repetição do projeto, proporcionou ainda mais racionalização e industrialização a essas instituições (Kowaltowski, 2013).

Kowaltowski (2013) aponta que os CIACs mantiveram o programa pedagógico idealizado por Anísio Teixeira, o inventor da escola pública no Brasil, o qual já havia proposto um sistema de educação integral visando à criança uma educação complementar dirigida ao desenvolvimento social, através de práticas desportivas, culturais, de ensino e voltadas à saúde.

Os CIACs foram resultado de um compartilhamento de atribuições entre as três esferas federativas. À União ficou a responsabilidade da elaboração do projeto arquitetônico, assim como de sua construção, aos Estados ficou a função de prover os recursos humanos responsáveis pela gestão da escola, e aos Municípios competia a disponibilização dos terrenos e a manutenção do prédio depois de construído (Coutinho, 2013).

Em virtude do impedimento do Presidente Collor, houve uma reorganização dos Ministérios, de forma que alguns programas do Governo foram alterados. Nessas mudanças o Projeto Minha Gente passou a ser denominado Programa Nacional de Atenção Integral à Criança e ao Adolescente - PRONAICA. O programa manteve seu objetivo inicial e sofreu pequenas alterações, apenas para haver certo distanciamento do Governo anterior (Coutinho, 2013; Sobrinho \& Parente, 1995). A partir desse momento os CIACs passaram a se chamar Centro de Atenção Integral à Criança e ao Adolescente (CAICs).

Para o Projeto Minha Gente, havia a meta de construção de 5.000 CIACs, porém, em sua reformulação para PRONAICA, esse número foi revisto para apenas 423 CAICs (Fonseca, 2010). Contudo, em 1997, após o encerramento do PRONAICA, realizado pelo então Presidente Fernando Henrique Cardoso, o Tribunal 
de Contas da União do Brasil apontou que haviam sido construídas 357 unidades no Brasil, tendo custado na época cerca de 1,5 bilhão de reais aos cofres públicos (Brasil, 1997).

Assim, busca-se responder a seguinte pergunta: Como os processos de apropriação são influenciados pelo projeto de arquitetura padrão em instituições de ensino a partir da visão de quem trabalha na escola? O objetivo deste artigo é identificar como ocorre a apropriação e a formação de identidade em uma escola de projeto padrão a partir da percepção de seus usuários.

\section{Metodologia}

Para responder à pergunta de pesquisa e atender ao objetivo deste trabalho, foi selecionado como estudo de caso o edifício do CAIC localizado na cidade de Pelotas, no estado do Rio Grande do Sul, na região Sul do Brasil. Esse município foi escolhido por ser referência em educação pública no sul do estado, possuindo 89 escolas municipais (Pelotas, 2020), 53 estaduais (RS, 2020), um Instituto Federal e uma Universidade Federal. Dessas escolas, três são exemplares de projeto padrão: Instituto Estadual de Educação Assis Brasil (1942), administrado pelo governo estadual; CIEP Osmar Rocha Grafulha (1994) conduzido, também, pela esfera Estadual, e o CAIC (1995) atualmente gerido pela Prefeitura Municipal de Pelotas (Figura 1). Dentre essas instituições, foi selecionado como estudo de caso o CAIC, único exemplar na cidade de Pelotas originado de um programa implementado a nível federal.

O CAIC da cidade de Pelotas instalado na localidade do sub-bairro Pestano, foi construído pela empresa Conesul Consórcios, sendo finalizado e entregue no ano de 1995 e inaugurado pelo Ministério da Educação em 1996. Ainda nos primeiros momentos de operação do CAIC, a ideia de uma nova proposta de escola com turno integral foi abandonada, sendo instalado em seu prédio a já existente Escola Municipal de Ensino Fundamental Francisco Caruccio.

Em 2001, a Prefeitura Municipal de Pelotas, aproveitando a setorização do prédio, dividiu a edificação entre três instituições (Figura 2). $\mathrm{O}$ espaço que era utilizado com pré-escola foi segmentado dos demais blocos para comportar a Escola Municipal de Educação Infantil Herbert de Souza. Dos ambientes voltados à saúde, parte foi desativada e transformada em salas de aula, e o restante tornou-se Unidade Básica de Saúde administrada pela Universidade Católica de Pelotas. A terceira parte permaneceu com a Escola Municipal de Ensino Fundamental Francisco Caruccio.

A abordagem metodológica adotada neste estudo é qualitativa e aplicou dois métodos de coleta de dados: observação, com levantamento físico do local, e entrevistas semiestruturadas. A primeira etapa, constituída pela observação e levantamento de campo, teve caráter investigativo e aconteceu no dia 20 de novembro de 2019, pela manhã, durante o período de atividades escolares no edifício. O objetivo dessa etapa foi conhecer o espaço e identificar seus usuários. Foram analisadas as características do ambiente construído, seu contraste com o entorno e a caracterização de seus usuários quanto às atividades desempenhadas na escola. 
A partir disso, aliada à pesquisa documental, para a segunda etapa, adotou-se entrevistas semiestruturadas como ferramentas para conhecer de maneira mais aprofundada a percepção dos usuários quanto ao prédio escolar. As entrevistas tiveram como objetivo (i) identificar intervenções na edificação e sua relação com o sentimento de representatividade e identidade de lugar, e (ii) ponderar como o fato de o edifício ser um projeto padrão influencia em sua apropriação e representatividade pelos seus usuários.

Observa-se que o prédio CAIC de Pelotas atende duas escolas de forma independente, além de uma unidade básica de saúde, e passou por descaracterizações em parte de sua construção. Portanto, conhecer a edificação antes de suas reformas, assim como presenciar o cotidiano da instituição, foram aspectos levados em consideração na escolha dos entrevistados. Dessa forma, escolheu-se entrevistar um funcionário-chave de cada escola de acordo com o tempo em que lá trabalham.

As entrevistas foram gravadas de maneira consensual e depois transcritas. As transcrições não foram editadas, de forma a se manter o coloquialismo da conversa, possibilitando a análise do discurso. Cada entrevista teve os trechos de sua transcrição classificados em categorias de análise. As perguntas das entrevistas focaram em tópicos referentes à história, às intervenções realizadas ao longo do tempo e à representatividade da edificação do CAIC para a comunidade escolar. Para estimular os entrevistados, foram apresentadas 12 fotografias que mostrassem o contraste das reformas ocorridas nas duas escolas, que funcionam na edificação, - Escola Municipal de Ensino Fundamental Francisco Caruccio e a Escola de Educação Infantil Herbert de Souza.

A primeira entrevista foi com um funcionário da Escola Municipal de Ensino Fundamental Francisco Caruccio, no dia 21 de novembro de 2019. A pessoa entrevistada é do sexo masculino, atua como professor nessa instituição há aproximadamente 11 anos e tem formação na área de história. A conversa foi desenvolvida em uma sala da escola, com duração aproximada de 50 minutos, em ambiente que tanto o pesquisador quanto o entrevistado estavam à vontade.

Referente à entrevista com um funcionário da Escola Municipal de Educação Infantil Herbert de Souza, não houve nenhum voluntário. A pessoa que atendeu ao pedido o fez, pois, seu superior imediato solicitou. A entrevistada é do sexo feminino e atua como auxiliar de educação infantil na instituição há 19 anos. A entrevista, que teve duração de 20 minutos, foi realizada no dia 26 de novembro de 2019, na biblioteca, com a presença de outros funcionários da escola que não interferiram, pelo menos de maneira ativa, no diálogo, que teve respostas curtas por parte da entrevistada. 


\section{Resultados}

O programa do CAIC na cidade de Pelotas no Brasil contemplou setores de anfiteatro, ginásio coberto, capacitação, creche, saúde, difusão cultural, educação escolar e educação voltada ao trabalho, horta e áreas externas. Nota-se sua amplitude, voltada, principalmente, a atividades de cunho social. O prédio, com características monumentais destoa de seu entorno devido a sua forma, sua tecnologia construtiva e seu tamanho, pois o bairro da comunidade local é composto maioritariamente por edificações residenciais populares.

A construção do CAIC foi proposta de forma setorizada com quatro blocos em sequência, ligados através de circulações horizontais (Figura 3). O primeiro bloco é o ginásio coberto, que engloba quadra poliesportiva, vestiários, depósito de materiais e ambiente administrativo. Esse espaço possui forma trapezoidal, com vidraças em suas fachadas frontais e sua cobertura prioriza ventilação e iluminação natural. O segundo prédio, único com dois pavimentos, é dividido na parte térrea pelos corredores em quatro partes, que se dedicam a oficinas de laboratórios e artísticas, área de serviços e no segundo pavimento atende espaços para salas de aula. O terceiro bloco serve às áreas destinadas à saúde e oficinas do trabalho. Enquanto o quarto bloco, com forma retangular, atende à educação infantil com pátio interno central.

Com o passar dos anos e o surgimento de manifestações patológicas na edificação, iniciou-se um processo de adaptações e reformas, principalmente na parte referente à Escola Municipal de Educação Infantil Herbert de Souza. A intervenção mais significativa aconteceu em 2017, em que foram realizadas as seguintes alterações somente no setor voltado à educação infantil: as esquadrias pivotantes em ferro foram substituídas por janelas de correr em alumínio, a cobertura em concreto foi alterada para telhas metálicas e os pátios internos ganharam fechamento em vidro (Figura 4). Ressalta-se que as demais instituições que funcionam no mesmo prédio, Escola Municipal de Ensino Fundamental Caruccio e a Unidade Básica de Saúde, não tiveram intervenções.

As modificações realizadas destoam do prédio original, seja pela diferenciação no material e técnica empregados ou na alteração da forma e na função de seus elementos, evidenciando, dessa maneira, a distinção entre a temporalidade que as intervenções evocam na edificação. Dentro da mesma construção percebe-se a diferenciação entre as instituições escolares através das mudanças mencionadas. Acreditando-se que isso seja uma evidência da utilização e apropriação da escola.

As categorias de análise (Tabela 1) obtidas pelas respostas das entrevistas foram: história da edificação; projeto padrão; programa de projeto; intervenções no edifício; representatividade, apropriação e preservação. Observa-se que, apesar de ambos os entrevistados fazerem parte do quadro de funcionários da Secretaria Municipal de Educação da cidade de Pelotas e atuarem na área da Educação há mais de 11 anos, o nível hierárquico dos cargos que ocupam são bem diferentes, o que ocasionou certa assimetria nas respostas obtidas, não sendo encontradas as cinco categorias de análise nas duas entrevistas. 


\section{Discussão}

$\mathrm{Na}$ realização da entrevista, ao serem perguntados sobre o quanto conhecem a respeito do histórico da escola, a partir das respostas do entrevistado da Escola Municipal de Ensino Fundamental Caruccio, pode-se notar grande apreço e conhecimento a respeito da história da escola, mesmo referente a períodos que o entrevistado não trabalhava na mesma; já a entrevistada da Escola Municipal de Educação Infantil Herbert de Souza não conhecia a trajetória da instituição. Na visita às escolas, pode-se perceber que a escola Caruccio, instituição com menos intervenções físicas, possuía grande número de painéis informativos, nos acessos e nos corredores, a respeito de sua história, enquanto na escola Herbert de Souza não havia esse tipo de material exposto.

Nas duas entrevistas realizadas, ao serem questionados sobre as diferenças desta escola para com as outras da cidade, os entrevistados relataram que percebem que a edificação em que trabalham é diferente das demais instituições escolares do município, seja por causa de sua forma, na arquitetura, ou devido aos ambientes diferenciados que a escola proporciona. O entrevistado da escola Caruccio relatou conhecer outras escolas CAIC, como as localizadas nas cidades de Rio Grande e Bagé. Já a entrevistada da escola Herbert de Souza não sabia que o prédio da escola pertenceu a um programa de educação federal, nem que aplicava um projeto padrão em todas as localidades que se instalava.

A partir da conversa com o professor da escola Caruccio a respeito do pensamento do entrevistado perante o programa da edificação, pode-se notar que a Unidade Básica de Saúde, que funciona atualmente onde era a ala médica da escola, é muito requisitada pelos usuários da escola, principalmente no que se refere aos atendimentos na área de psicologia, clínica médica e obstetrícia. Esse fato mostra a coesão e a fundamentação do programa do projeto original e, nesse sentido, ambos os entrevistados relatam que o programa de necessidades da edificação atente bem as atuais demandas escolares, apesar de ter sido lançado há 30 anos.

Nas duas entrevistas houve reclamações quanto ao conforto térmico, à implantação no lote e às manifestações patológicas encontradas na edificação, destacando-se, no último caso, as infiltrações originadas na cobertura em argamassa armada. Tal fato consolida a ideia de que as inconsistências projetuais acontecem pela padronização do projeto disseminado em todo o país, desconsiderando particularidades climáticas, de acesso à mão de obra que domine as técnicas construtivas adotadas e de implantação no lote, conforme os argumentos de Tedeschi (1978), Gaite (2003) e Kowaltowski (2013).

O problema referente à implantação da edificação fica evidente quando analisada a inserção da construção no bairro e no lote na cidade de Pelotas (Figura 5), pois o que seria o acesso principal da escola fica direcionado a um terreno vacante, enquanto atualmente a entrada na escola se dá pelo que seria o portão dos fundos, em uma via auxiliar sem pavimentação. $O$ posicionamento da escola no bairro priorizou questões de visibilidade e destaque do prédio perante o conforto e a facilidade de acesso. Essa alteração no acesso do edifício muda o planejamento de fluxo horizontal 
e a referência visual do prédio conforme definido pelo projetista.

A partir do discurso de ambos os entrevistados, nota-se que eles sentem afeto pela escola, que ela os representa e que é motivo de orgulho fazerem parte da comunidade escolar. Ao serem questionados sobre a existência do sentimento de identificação, representação e apego pela escola, os dois entrevistados apontam que os habitantes do bairro também percebem esse sentimento de pertencimento, comprovando a existência de apropriação e representatividade.

Segundo o professor da escola Caruccio, isso acontece, pois o diretor da escola tem uma relação de diálogo com todas as lideranças do bairro, incluindo proprietários de mercados e locutores de veículos de comunicação, o que aproxima até os moradores locais que não têm envolvimento direto com a instituição. $O$ entrevistado comenta que há carinho e reconhecimento dos alunos para com seu diretor, o que provoca confiança e acolhimento no ambiente escolar, o que também influencia na apropriação do edifício. Deve-se levar em consideração que a escola, há 19 anos, já funciona da maneira em que está dividida atualmente, período em que, possivelmente, já foi construída uma nova representação identitária em seus usuários, diferente do modelo padrão original.

Em uma alusão às ideias de ruptura apresentadas por Gutiérrez (1989), os entrevistados foram questionados a respeito do contraste da edificação escolar implantada 1995, perante as outras construções do bairro, e do contraste da edificação atual, após sua reforma de 2017. Foi constatado que não houve sentimento de ruptura, nem em 1995 e nem atualmente, pelo contrário houve ânimo e vontade por parte dos usuários de apropriarem-se. Fica claro que os entrevistados percebem que a edificação da escola destoa, de maneira a se destacar no bairro, do seu entorno, tanto em função de sua forma, como de suas dimensões e materiais construtivos.

Percebe-se que após a reforma do prédio, em que a escola teve sua forma alterada, seu uso continuou o mesmo. Levando em consideração as ideias de Shamai (1991), entende-se que as intervenções não ocorreram devido à falta de senso de lugar e sim em função dele, pois foi relatado o apreço e apego pelo local. A funcionária da escola Herbert colocou a reforma como muito positiva, fato que aumenta a apropriação do ambiente construído por esse usuário. É válido observar que a administração financeira nas duas instituições acontece de forma diferente. $\mathrm{Na}$ Escola Municipal de Educação Infantil Herbert de Souza todo investimento é aplicado e gerido com recursos da Prefeitura Municipal, enquanto na Escola Municipal de Ensino Fundamental Francisco Caruccio há utilização de recursos próprios, limitados pelo FNDE, o que proporciona autonomia em suas decisões, porém restringe seus gastos e reformas.

Acredita-se que por esse motivo os entrevistados colocaram que a preservação das características originais da edificação se relaciona à transparência e à autonomia na administração dos recursos financeiros da instituição. À transparência porque quando os usuários da escola sabem como e em que é aplicado o recurso, eles valorizam mais o ambiente, e a autonomia permite liberdade de escolha para definir o que será realizado com o recurso. Isso explica o porquê da escola Herbert de Souza estar mais 
descaracterizada. A reforma ocorrida em 2017, que acarretou alterações na edificação somente na parte referente à Escola Herbert de Souza, foi uma tentativa de sanar problemas oriundos da estandardização do projeto, ainda que tenha descaracterizado o edifício. Essa reforma evidencia a apropriação do prédio mostrando que, apesar do tempo passado, a utilização e o apreço pelo ambiente são constantes, somente a forma do prédio foi renovada.

Os resultados do estudo mostram que o projeto padrão impõe um ideal aos seus usuários, tanto no uso como na forma e função do edifício, o que provoca inconsistências com a realidade cultural da comunidade local, acarretando adaptações no ambiente construído, para que ocorra correspondência entre as pessoas e prédio. O CAIC, enquanto edificação, apesar de ser apreciado e apropriado, pode ser considerado um elemento de ruptura identitária por sua singularidade, tanto na arquitetura, quanto na monumentalidade e nos materiais construtivos. Percebe-se que enquanto a comunidade não for participativa no processo de projeto existirão incoerências entre as necessidades reais e as planejadas, o que pode ocorrer em qualquer tipo de edificação padrão.

\section{Considerações finaisConsiderações finais}

Entende-se que os resultados obtidos através da análise do estudo de caso aqui investigado, pode refletir a situação de outras instituições escolares que possuem um projeto padrão, sendo possível concluir que as intervenções realizadas em uma edificação padrão, com o intuito de renová-la sem alterar seu uso, podem ser consequência das demandas dos usuários devido as suas apropriações e utilização. $\mathrm{O}$ emprego do mesmo projeto arquitetônico em diferentes localidades provoca desajuste no sentimento de pertença da comunidade em que foi inserido, fazendo com que ocorram reformas e adaptações. A partir da ideia do senso de lugar, percebe-se que as intervenções no espaço construído são uma forma de superar e equilibrar esse desajuste, evidenciando seu apego e representatividade.

É de se esperar que edificações padronizadas, implantadas em localidades de forma a não considerar as particularidades da comunidade que irá utilizá-la, sejam submetidas a reformas e alterações para superar as divergências entre o projeto original e a real necessidade de seus usuários. As recentes obras no CAIC de Pelotas, apesar de descaracterizá-lo perante seu projeto original, foram tentativas de soluções para as inconsistências originadas a partir da uniformização de projeto, sejam relacionadas ao clima ou aos métodos construtivos.

Pode-se perceber que o programa pedagógico dos CAICs, assim como o de arquitetura, pouco mudou em relação às escolas padrão mais antigas, como as idealizadas por Anísio Teixeira e Darcy Ribeiro, o que mostra sua solidez e fundamentação, fato evidenciado quando os entrevistados relatam que os ambientes, planejados há 30 anos, atendem bem suas necessidades pedagógicas atuais. Entretanto, o mesmo não pode ser dito a respeito de sua materialização no projeto de arquitetura e posteriormente em sua construção, visto que em virtude das inovações tecnológicas foram permitidas novas metodologias construtivas e soluções projetuais, que não se 
adaptaram às particularidades locais do bairro.

O estudo aqui apresentado teve seus resultados alinhados com o proposto pela bibliografia analisada, uma vez que as intervenções no projeto padrão podem ser entendidas como a transformação do lugar, deixando-o mais representativo e confortável para seus ocupantes. Há a percepção da potencialidade do lugar por parte da administração pública e da comunidade local do estudo de caso, entendendo-se as intervenções e reformas como resultado da apropriação da escola.

\section{Declaração de conflito de interessesDeclaração interesses}

Os autores declaram que não tem conflito de interesse de ordem financeiro, comercial, político, acadêmico e pessoal. 


\section{Figura 1}

Instituições de ensino com projeto padrão na cidade de Pelotas no Brasil: Instituto Estadual de Educação Assis Brasil (acima à esquerda); Centro Integrado de Educação Pública Osmar Grafulha (acima à direita) e Centro de Atenção Integral à Criança e ao Adolescente (abaixo).

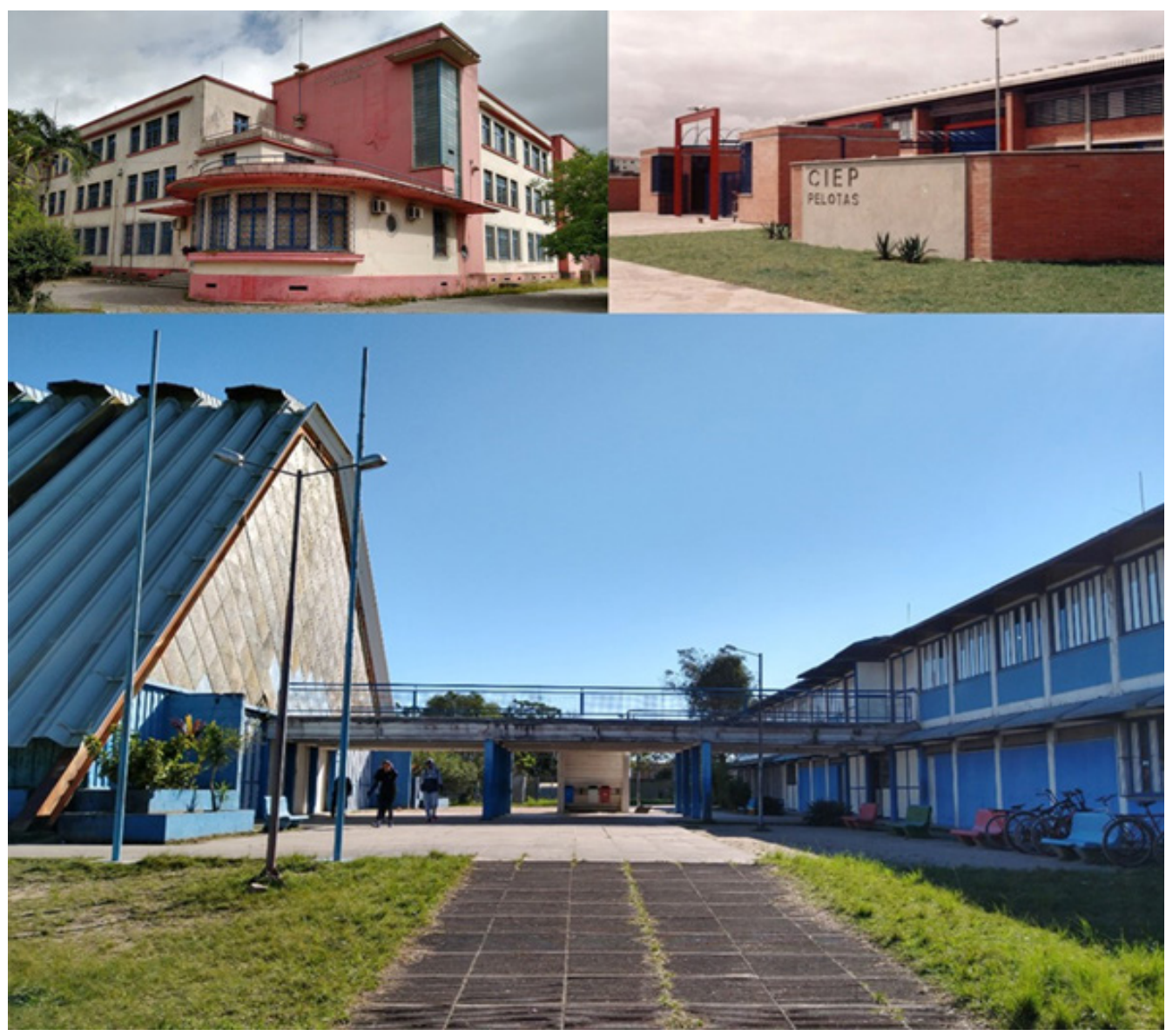

Fonte: autores (2020); Assembleia Legislativa do Rio Grande Do Sul (2013). 


\section{Figura 2}

Divisão da planta baixa do prédio do CAIC em Pelotas em três instituiçôes.

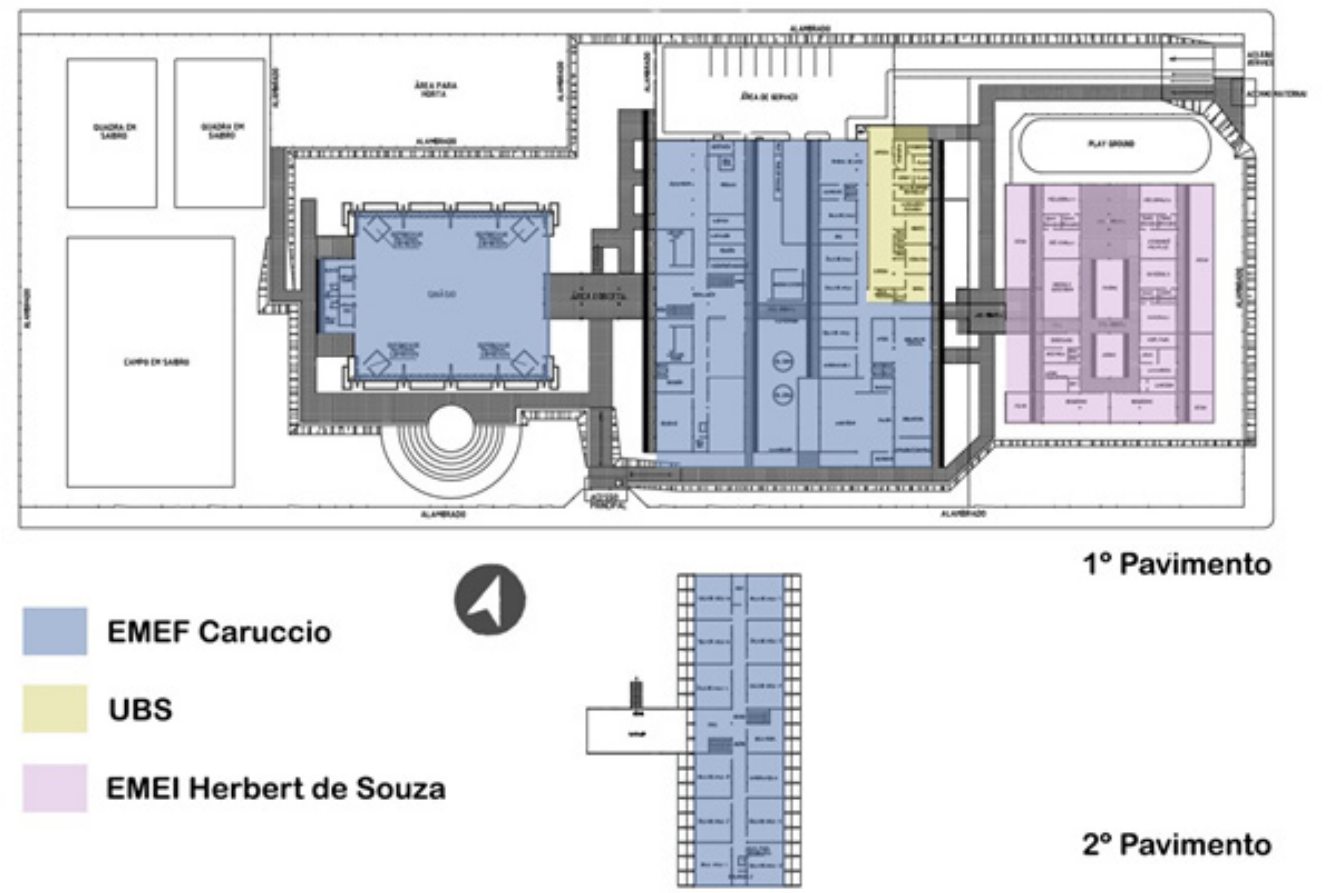

Fonte: Secretaria Municipal de Educação e Desporto de Pelotas, planta baixa de 1993.

\section{Figura 3}

Setorização das atividades no prédio do CAIC na cidade de Pelotas.

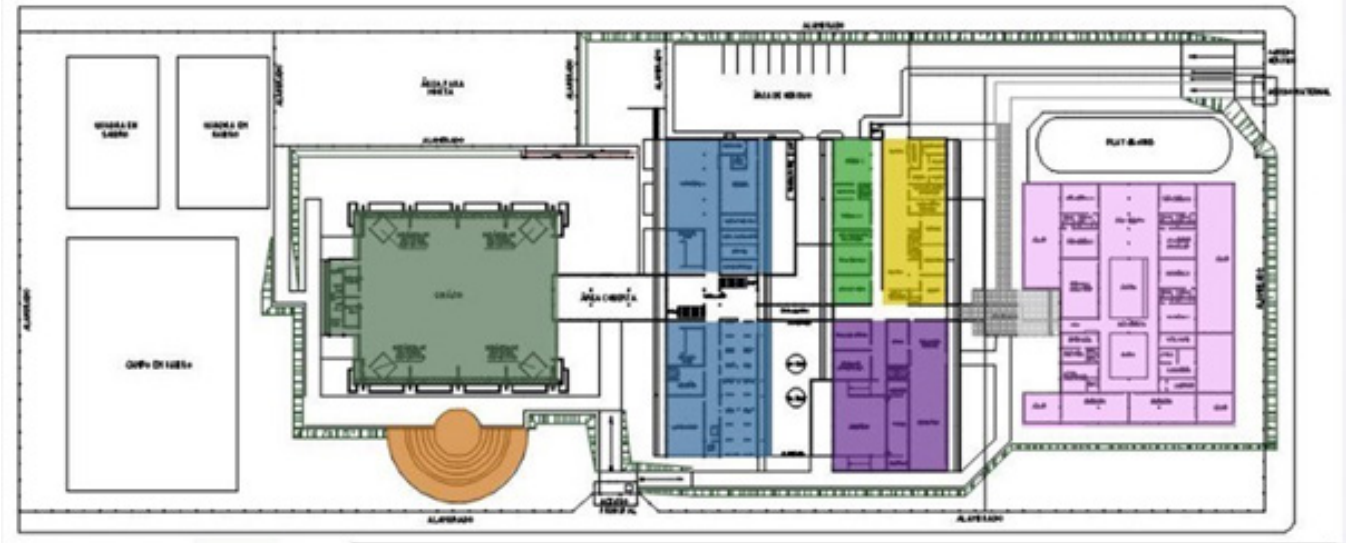

Ginásio
Creche
Saúde
Capacitação
Anfiteatro
Dif. Cultural
Ed. Trabalho
Ed. Escolar

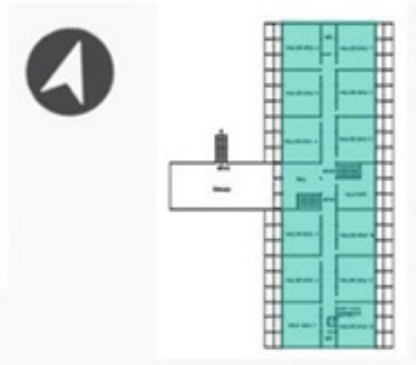

$1^{\circ}$ Pavimento

Fonte: Secretaria Municipal de Educação e Desporto de Pelotas, planta baixa de 1993. 


\section{Figura 4}

Alteraçôes realizadas na edificação do CAIC em Pelotas em reforma de 2017. No início da reforma e após a reforma.

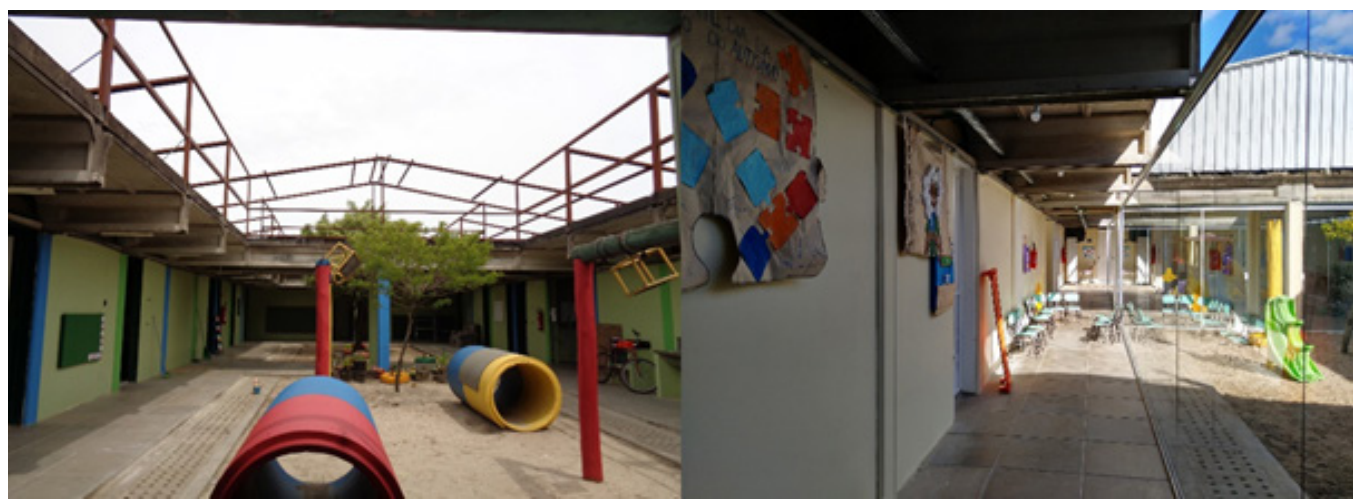

Fonte: Secretaria Municipal de Educação e Desporto de Pelotas, 2019; autores, 2019.

\section{Figura 5}

Vista aérea do prédio CAIC em Pelotas.

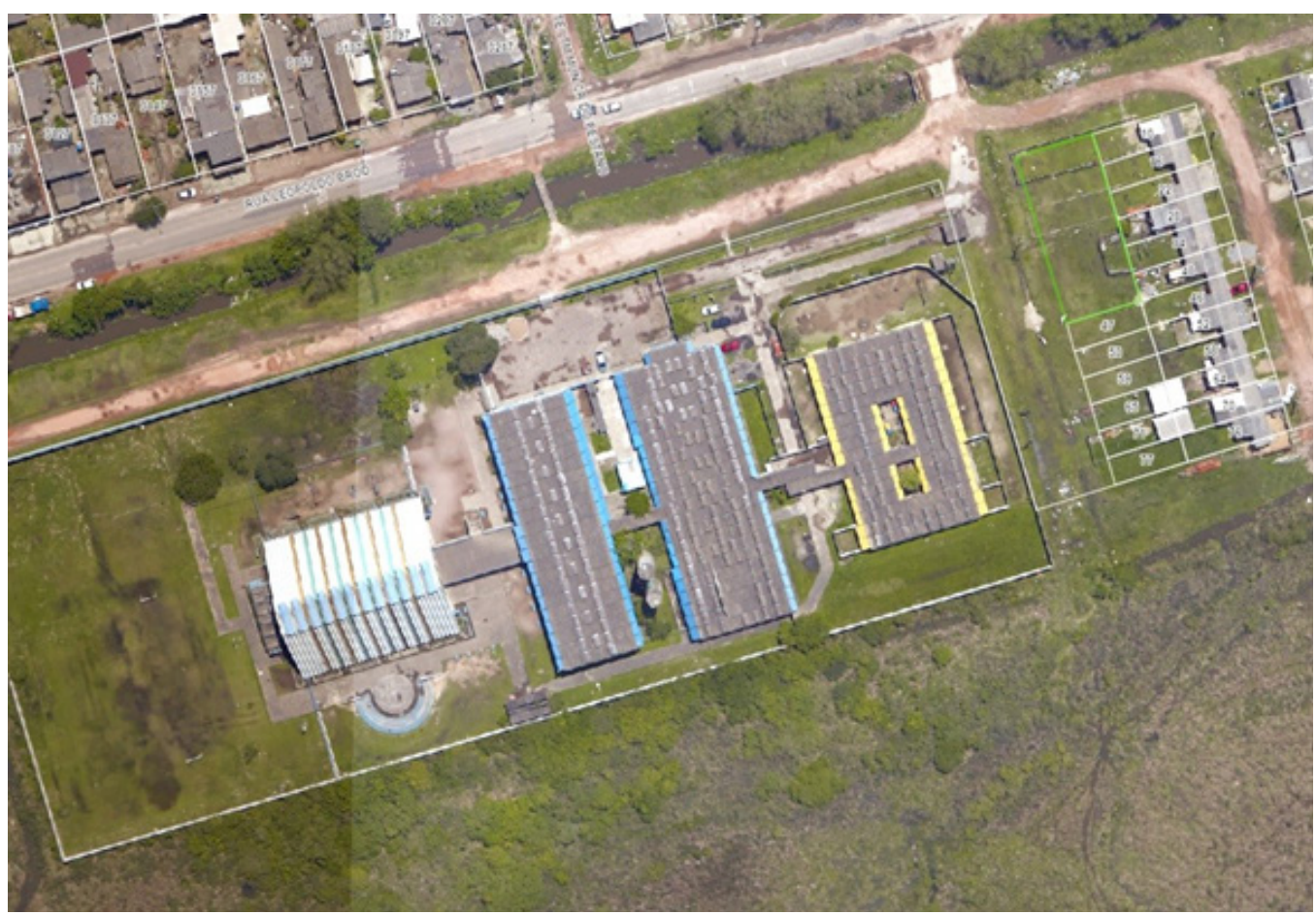

Fonte: GeoPelotas, 2020. 


\section{Tabela 1}

Categorias de análise obtidas das transcrições das entrevistas realizadas.

\begin{tabular}{|c|c|c|}
\hline Categoria & Descriçâo & Citaçâo \\
\hline $\begin{array}{l}\text { Conhecimento histórico } \\
\text { a respeito do CAIC } \\
\text { Pelotas/RS }\end{array}$ & $\begin{array}{c}\text { Se corhece a história da } \\
\text { edificaçzio do CAIC em } \\
\text { Pelotas/RS }\end{array}$ & $\begin{array}{l}\text { "Eu corheço bastante a historia da escola. } \\
\text { Porque eu participei da festa de aniversario } \\
\text { da escola dos... cinquenta anos da escola e } \\
\text { agora, depois, dos setenta e cinco. Conheço } \\
\text { bem a historia, sim. Professor da EMEF } \\
\text { Caruccio }\end{array}$ \\
\hline $\begin{array}{l}\text { Percepção sobre o } \\
\text { projeto padrâo }\end{array}$ & $\begin{array}{l}\text { O que sente a respeito } \\
\text { da edificaçżo ser um } \\
\text { projeto padrão } \\
\text { replicado no Brasil }\end{array}$ & $\begin{array}{c}\text { "Porque se a gente for amalisar o tipo de } \\
\text { ginźsio e o tipo de aberturas que o CAIC } \\
\text { tem, para o Rio Grande do Sul, nio è o } \\
\text { ideal." Professor da EMEF Caruccio } \\
\text { "Talver năo fosse o modelo melhor pra } \\
\text { regiżo sul do Brasil..." Professor da EMIEF } \\
\text { Caruccio. } \\
\text { ".. aqui no inverno é muito frio. Muito frio } \\
\text { no invemo e muito calor no verio." } \\
\text { Professor da EMEI Herbert de Souna }\end{array}$ \\
\hline $\begin{array}{l}\text { Qualidade do programa } \\
\text { da edificaçäo }\end{array}$ & $\begin{array}{l}\text { Se o programa da } \\
\text { edificação, planejado } \\
\text { na decada de } 1990 \text {. } \\
\text { atende as necessidades } \\
\text { atuais }\end{array}$ & $\begin{array}{l}\text { "... é um projeto que se aprosima daquilo } \\
\text { que eu entendo que é o ideal. Ora, eu tenho } \\
\text { auditorio, eu tenho ginasio, eu tenho } \\
\text { laboratorios de informatica, eu tenho uma } \\
\text { infraestrutura aqui gigantesca, } \\
\text { maravilhosa..." Professor da EMEF Caruccio }\end{array}$ \\
\hline Reformas no edificio & $\begin{array}{l}\text { Sentimento relacionado } \\
\text { da intervençóes no } \\
\text { edificio em } 2017 \text {, } \\
\text { mesmo causando } \\
\text { diferenciaçóes no } \\
\text { ambiente construido }\end{array}$ & 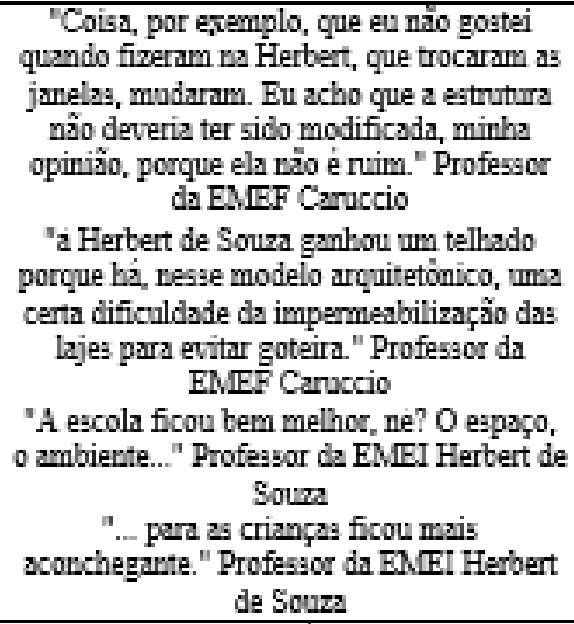 \\
\hline $\begin{array}{l}\text { Representatividade, } \\
\text { apropriação e } \\
\text { preservação }\end{array}$ & $\begin{array}{l}\text { Se há o sertimento de } \\
\text { identificação e } \\
\text { representação com o } \\
\text { edificio escolar e } 5 e \\
\text { esse sentimento }\end{array}$ & $\begin{array}{l}\text { "... eu acho que esse predio simboliza muito } \\
\text { para comunidade e eles têm orgulho de ter } \\
\text { essa escola diferente arquitetonicamente das } \\
\text { outras. Eles tém! Bles tếm orgulho! Bles têm } \\
\text { orgullko!" Professor da EMIEF Caruccio }\end{array}$ \\
\hline
\end{tabular}




\section{Referências}

Augé, Marc. (1995). Não-Lugares: Introdução a uma antropologia da supermodernidade. Papirus.

Azevedo, G., Bastos, L. \& Blower, H. (2007). Escolas de ontem, educação hoje: é possível atualizar usos em projetos padronizados? Cadernos Proarq. Revista do Programa de Pós-graduação em Arquitetura da UFRJ:n. 11, pp. 57-64.

Brasil. Presidência da República (1991). Decreto de 14 de maio de 1991. Dispõe sobre o Projeto Minha Gente e dá outras providências. Disponível em: http://www.planalto.gov.br/ccivil 03/DNN/Anterior\%20a\%202000/1991/ Dnn139.htm\#: :text=DECRETO\%20DE\%2014\%20DE\%20MAIO, GENTE $\% 2$ C $\% 20 \mathrm{e} \% 20 \mathrm{~d} \% \mathrm{C} 3 \% \mathrm{~A} 1 \% 20$ outras $\% 20$ provid $\% \mathrm{C} 3 \%$ AAncias. Acesso em: Dezembro de 2019.

Brasil. Tribunal de Contas da União (1997). Decisão 468/97: Plenário - Ata 30/97. (Processo $\mathrm{n}^{\mathrm{o}}$ TC 016.305/96-5. Responsável: José Antônio Carletti. Relator: Ministro Marcos Vinicios Vilaça. Data da sessão: 06 de agosto de 1997. Diário Oficial da União: 20 de agosto de 1997) http://www.tcu.gov.br/Consultas/Juris/ Docs/judoc\%5CDec\%5C19970608\%5CGERADO_TC-19482.pdf.

Cabral, L. K. (2020). Arquitetura Art Déco nas escolas do Rio Grande do Sul no período do Estado Novo (1930-1950). [Dissertação de mestrado, Universidade Federal de Pelotas, Pelotas, Brasil].

Corrêa, M., Mello, M., \& Neves, H. (1991). Arquitetura Escolar Paulista: 1890-1920. Fundação para o desenvolvimento da educação -FDE, diretoria de obras e serviços.

Coutinho, M. (2013). A História Da Educação Integral Em Seropédica A Experiência Do Caic. In: VII Congresso Brasileiro da História da Educação. Anais [...]. 14p. Disponívelem:http://sbhe.org.br/novo/congressos/cbhe $7 / \mathrm{pdf} / 07 \% 20$ HISTORIA $\% 20$ DAS $\% 20$ INSTITUICOES $\% 20 \mathrm{E} \% 20$ PRATICAS $\% 20$ EDUCATIVAS/A \%20H I S T O R I A \% 20 D A \% 20 E D U C A C A O \% 20 INTEGRAL\%20EM\%20SEROPEDICA.pdf. Acesso em: dezembro de 2019.

Dórea, C. (2000). Anísio Teixeira e a Arquitetura Escolar: Planejando escolas, construindo sonhos. Revista da FAEEBA. N¹3. 151-160p.

Faria Filho, L. M., \& Vidal, D. G. (2000). Os tempos e os espaços escolares no processo de institucionalização da escola primária no Brasil. Revista brasileira de educação, v. 14.

Fundo Nacional de Desenvolvimento da Educação - Ministério da Educação (2017). Proinfância. Acessado em 03 de jun. de 2020. Online. Disponível em: https:// www.fnde.gov.br/index.php/programas/proinfancia/eixos-de-atuacao/ projetos-arquitetonicos-para-construcao/item/4816-tipo-b 
Fonseca, M. (2010). Resgate Da História De Implantação Do Centro De Atenção Integral A Criança Paulo Dacorso Filho Na UFRRJ E A Perspectiva De Sua Transformação Em Um Centro De Ensino E Pesquisa Aplicado A Educação Agroecológica. [Dissertação de Mestrado, Universidade Federal Rural do Rio de Janeiro, Rio de Janeiro, Brasil].

Frampton, K. (2003). História Crítica da Arquitetura Moderna. Martins Fontes.

Gaite, A. (2003). Diseño y Región: Arquitectura Apropriada. Nobuko.

Gutiérrez, R. (1989). Arquitetura Latino - Americana: Textos para reflexão e polêmica. Editora Nobel.

Kowaltowski, D. C. C. K. (2013). Arquitetura Escolar: O Projeto do Ambiente de Ensino. Oficina de textos.

Oliveira, F. (2007). Arquitetura Escolar Paulista nos anos 30. [Dissertação de mestrado, Universidade de São Paulo, São Paulo, Brasil].

Pelotas. Secretaria Municipal de Educação e Desporto (2020). Portal Municipal da Educação e Desporto - Escolas. Acessado em 03 de jun. 2020. Online. Disponível em: http://site.pelotas.com.br/educacao/portal/escolas/

Ramón, J. \& Pereira A. (2010). Introdução à história da arquitetura, das origens ao século $X X I$. Bookman.

RS. Governo do Estado do Rio Grande do Sul - Secretaria Estadual de Educação (2020). Busca de escolas. Acessado em 03 de jun. de 2020. Online. Disponível em: https:// educacao.rs.gov.br/busca-de-escolas

Segawa, H. (1997). Arquiteturas no Brasil 1900-1990. EDUSP, acadêmica 21.

Schwartzman, S. (1982). Estado Novo, um Autorretrato (Arquivo Gustavo Capanema). Coleção Temas Brasileiros, Universidade de Brasília, volume 24.

Shamai, S. (1991). Sense of place: an empirical measurement. Geoforum Vol. 22, No. 3, 347-358.

Sobrinho, J. A, \& Parente, M. M. (1995) CAIC: Solução ou Problema? Texto para discussão $n^{o}$ 363. Repositório do Conhecimento do IPEA. Brasília/DF, Brasil.

Tedeschi, E. (1978). Teoría de la arquitectura. Nueva Visión.

Waisman, M. (1985). La estrutura histórica del entorno. Nueva Visión. 